\title{
Numerical Modeling and Experimental Verification for High-Speed and Heavy-Load Planar Mechanism with Multiple Clearances
}

\author{
Fangang Meng, Shijing Wu, Fan Zhang, and Liang Liang \\ School of Power and Mechanical Engineering, Wuhan University, Wuhan 430072, China \\ Correspondence should be addressed to Shijing Wu; wsj@whu.edu.cn and Liang Liang; liangliang@whu.edu.cn
}

Received 3 July 2015; Revised 28 August 2015; Accepted 8 September 2015

Academic Editor: Mohammed Nouari

Copyright (C) 2015 Fangang Meng et al. This is an open access article distributed under the Creative Commons Attribution License, which permits unrestricted use, distribution, and reproduction in any medium, provided the original work is properly cited.

\begin{abstract}
Transmission mechanism is one of the most important parts of the Ultra-High Voltage (UHV) circuit breaker. It has specific characteristics such as fast response, high speed, and heavy load in the processes of open and close actions. This paper studies the effects of multiple clearances on the working characteristics of transmission mechanism system, especially the motion of its journal center path during operation. It builds a nonlinear kinetic model of transmission mechanism considering the system energy losses due to the impact and friction between the journal and bearing inside clearance joints. Also, an experimental platform is built to measure the displacement and velocity of the moving contact. The results show that the existence of 15 clearance joints in our mechanism system can cause hysteresis effects on the velocity and acceleration of the moving contact, as well as its acceleration fluctuation. Meanwhile, the increase of friction coefficient will stabilize the dynamic characteristic. In addition, both the experimental and simulation results indicate that the motion of the journal center, which is unevenly distributed along the circle, is characterized by three phases: free flight motion, contact motion, and impact motion.
\end{abstract}

\section{Introduction}

Accurate prediction for dynamic behavior of mechanism is more and more important with the development of precision machinery project. Dynamic characteristic of mechanism is becoming one key concern of domestic and international mechanical engineering [1-3]. Clearances in mechanism are unavoidable to assemblage, manufacturing errors, and wear. It occurs in each active joint with the movement of mechanism and influences the motion accuracy. Over the last few decades, there are many scholars who have done a great number of researches on the dynamic analysis with imperfect joints by using theoretical and experimental approaches. For example, Flores et al. [4-6] proposed a significant number of different methodologies on the dynamics of planar and spatial mechanisms in revolute and cylindrical joints with or without lubrication conditions. Mukras et al. $[7,8]$ established a dynamic model of the planar mechanism with clearance, using the Archard model to explore the influence of the wear on the mechanism. The results indicated that the dynamic response of the mechanism is similar under two situations, but the difference in the abrasion level was large. In $[9,10]$, the effects of joint clearances on mechanism path generation and transmission quality were studied by assuming four-bar and slider-crank mechanism having rigid links.

Most of these works, however, are somewhat limited because they have focused on the general multibody systems without flexible bodies. The authors of [11, 12] investigated the elasticity of the connecting rods in mechanisms with clearance joint using absolute nodal coordinate formulation based on Lankarani and Nikravesh's continuous force law and Coulomb's friction law. And the authors of [13] also proposed a new EHD lubricated cylindrical model developed under the framework of flexible multibody formulation. The lubricated cylindrical joints in a flexible multibody system are described by using absolute coordinate based method, which combines the natural coordinate formulation for rigid bodies and the absolute nodal coordinate formulation for 
flexible bodies. Zhang et al. [14] presented a computer-aided analysis and the framework of the DOE modeling to study the effect of the joint clearance size, input crank speed, and material/contact stiffness coefficient on the dynamic response of a multibody system with one clearance joint. At the same time, they used the Kriging metamodel to replace the computer simulation experiment as a cost-effective mathematical tool for optimizing the system performance. Varedi et al. [15] proposed an optimization method to alleviate the undesirable effects of joint clearance in a planar slider-crank mechanism and an algorithm based on PSO solved this highly nonlinear optimization problem. The result shows that its system response substantially changes with the joint clearance introduced.

Over the past few decades, a good number of theoretical and experimental studies have been proposed to model and analyze the clearance mechanisms. Liu et al. [16] compared five friction models on the same test-bed of the micro stickslip motion system. In this experimental study, it is concluded that LuGre friction model has the best accuracy among these five friction models. Khemili and Romdhane [17] studied the dynamic characteristic of a planar flexible slider-crank mechanism with clearance; the simulation and experimental results show that the link's flexibility has a role of suspension. Koshy et al. [18] used the commercial software to compute the intrajoint contact forces developed at the dry clearance joints and established an experimental to verify and validate this computational approach. Similarly, Erkaya et al. [19] proposed a numerical model for a slider-crank mechanism which includes one flexible body and two revolute joints with clearances and designed a test rig to study the effects of joint clearance on the dynamics of a partly compliant mechanism.

In these works, the research object was only a simple slider-crank mechanism or four-bar mechanism. The dynamic model of multibody system usually neglects clearance joint, because considering it will make the dynamic analysis more complex, especially for the mechanical system of high speed and heavy load. The UHV circuit breaker studied in the paper consists of 15 components, driving link, lower turn arm, insulating pole, upper turn arm, moving contact, and so forth. It has characteristics such as fast response, high speed, and heavy load in on-off process, and the instantaneous velocity can even reach up to $20 \mathrm{~m} / \mathrm{s}$. In this work, a method of combining theoretical analysis, numerical simulation, and physical experiment is proposed to research its characteristics when it is working. A nonlinear dynamic model of multilink transmission mechanisms with clearance using the Lankarani and Nikravesh contact theory and the modified Coulomb friction model is established on the basis of difference between experiments and simulation. The contact model used to simulate contact force in the clearance joints is based on subroutines "cnfsub.c". Such model assumes that the components inside the system are rigid bodies, which means ignoring the elastic deformation during the process of work. The energy losses of the system during the whole motion phase are caused by the frictions, contacts, and impact between clearance joints.

After an introduction, this paper is organized as follows: A contact force model based on clearance vector model

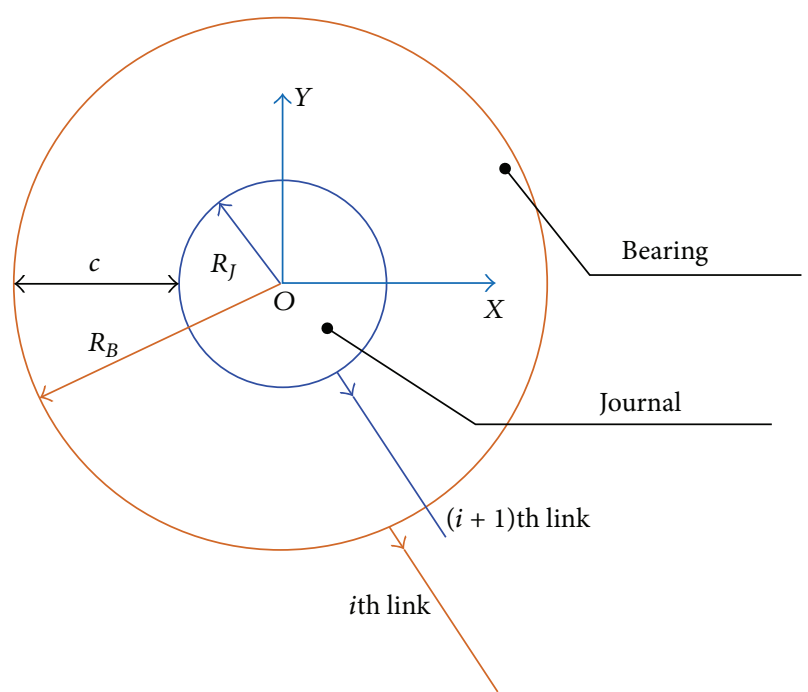

FIgURE 1: Planar revolute joint with clearance.

of clearance joint is established in Section 2. The physical structure and dynamic model of the transmission mechanism with multiple clearances for UHV are described in Section 3. Numerical simulations of the dynamic model are described and detailed discussion of the obtained results is presented in Section 4. Finally, the model for the transmission mechanism of UHV is summarized and the conclusions are also outlined in Section 5.

\section{Contact Force Models of Clearance}

2.1. Mathematic Model. A planar revolute joint with clearance is shown in Figure 1. It is assumed that the positional tolerance of the revolute joint is neglected. The difference in radius direction between the bearing and journal represents the size of the radial clearance. And it is defined as follows:

$$
c=R_{B}-R_{J},
$$

where $R_{B}$ and $R_{J}$ represent the radius of bearing and journal.

Figure 2 depicts the three different types of motion between the bearing and journal during dynamic of the realistic revolute joint: (a) free flight mode; (b) impact mode; (c) contact mode, where $O_{i}$ and $O_{i+1}$ are the centers of bearing and journal and $\mathbf{r}_{i}$ and $\mathbf{r}_{i+1}$ represent the position vectors of bearing and journal in the global inertia coordinate. Thus, clearance vector can be given by

$$
\mathbf{e}_{i}=\mathbf{r}_{i+1}-\mathbf{r}_{i},
$$

where $\mathbf{e}_{i}$ represents the eccentric vector of journal relative to bearing. So the eccentricity of bearing and journal can be described as

$$
\left|e_{i}\right|=\sqrt{e_{x}^{2}+e_{y}^{2}}
$$

The unit normal vector at the contact point of the bearing and journal is represented as

$$
\mathbf{n}=\frac{\mathbf{e}_{i}}{\left|e_{i}\right|}
$$




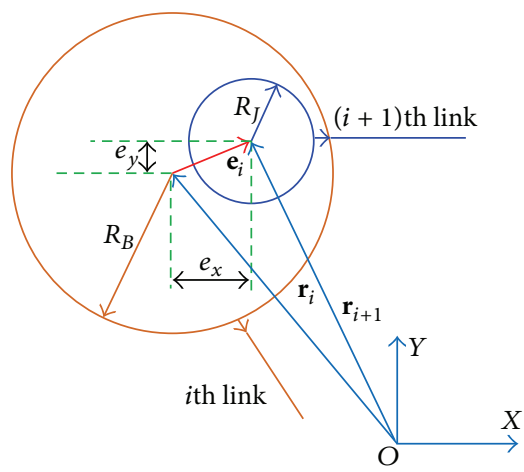

(a) Free light mode

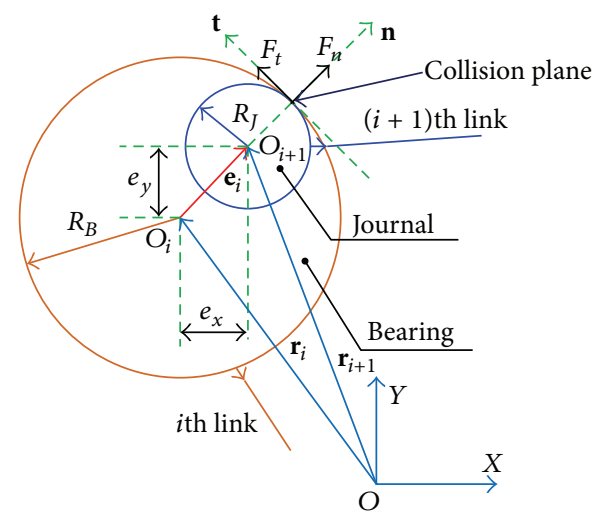

(b) Impact mode

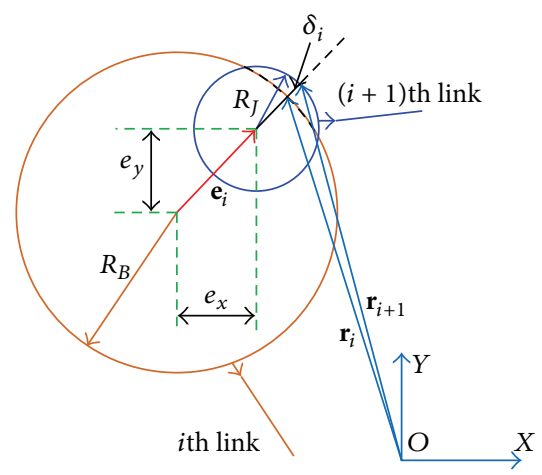

(c) Contact mode

FIgURE 2: Different types of motion.

Figure 2(c) describes the relative penetration depth between the bearing and journal, which are represented in global coordinate system. The penetration depth caused by collision between bearing and journal can be stated as follows:

$$
\delta=\left|e_{i}\right|-c .
$$

The situation where the contact is lost corresponds to $\delta<0$ (Figure 2(a)), whereas the contact with local deformation, referred to as a penetration, corresponds to $\delta>0$ (Figure 2(c)).

Contact between moving objects can be divided into collision and continuous contact. The collision refers to change of relative velocity of two objects at the moment of contact while one object has relative movement with another. This process is accompanied by deformation and sound. The continuous contact between two objects means that two surfaces interact with each other without penetration and this effect continues for some time.

The contact is detected by a change of sign in the penetration depth $\delta$ between the discrete moments in times $t_{n}$ and $t_{n+1} . \delta\left(q\left(t_{n}\right)\right)$ and $\delta\left(q\left(t_{n+1}\right)\right)$ denote the relative position array of the potential contact point between bearing and journal in the clearance joint at the time of $t_{n}$ and $t_{n+1}$, respectively, if they satisfy that

$$
\delta\left(q\left(t_{n}\right)\right) \delta\left(q\left(t_{n+1}\right)\right)<\mathbf{0} .
$$

There is at least one switch point located in the interval of $\left[t_{n}, t_{n+1}\right]$. This zero crossing of $\delta(q(t))$ can be found with the help of Newton-Raphson procedure.

It is important to estimate the loss of energy in the contact course between bearing and journal, so it is necessary to calculate the relative speed between their surfaces. The normal speed and tangential speed of the potential contact point can be expressed:

$$
\begin{aligned}
& v_{n}=(\dot{\delta})^{T} \mathbf{n}, \\
& v_{t}=(\dot{\delta})^{T} \mathbf{t},
\end{aligned}
$$

where the unit tangential vector $\mathbf{t}$ at the contact point of the bearing and journal can be achieved by reversing the unit normal vector $\mathbf{n}$ for $90^{\circ}$.

2.2. Normal Force Model. The Lankarani and Nikravesh contact force model is widely used for contact-impact process of mechanism system with joint clearance.

It is clear that the spring contact model can be expressed as

$$
F_{n}=K \delta^{n}+D(\delta) \dot{\delta},
$$

where $K \delta^{n}$ represents the elastic deformation force, $D(\delta) \dot{\delta}$ represents the energy dissipation, $\delta$ is the penetration depth, and $\dot{\delta}$ is the relative impact velocity. The exponent of the force deformation characteristic, $n$, depends on the material of the contact surfaces ( $n$ is set to 1.5 for metallic material) [20]. $D(\delta)$ is the instantaneous damping coefficient, which can be given by

$$
D(\delta)=\frac{3 K\left(1-c_{e}^{2}\right) \delta^{n}}{4 \dot{\delta}^{-}},
$$

where $c_{e}$ is restitution coefficient and the stiffness parameter $K$ can be calculated as follows:

$$
\begin{gathered}
K=\frac{4}{3\left(\sigma_{1}+\sigma_{2}\right)}\left[\frac{R_{1} R_{2}}{R_{1}+R_{2}}\right]^{1 / 2}, \\
\sigma_{i}=\frac{\left(1-v_{i}^{2}\right)}{E_{i}} \quad(i=1,2), \\
\frac{1}{E^{*}}=\frac{\left(1-v_{1}^{2}\right)}{E_{1}}+\frac{\left(1-v_{2}^{2}\right)}{E_{2}},
\end{gathered}
$$

where $R_{1}$ and $R_{2}$ represent, respectively, the radii of bearing and journal, $v_{i}$ is Poisson ratio, and $E_{i}$ is Young's modulus for element $i$. 


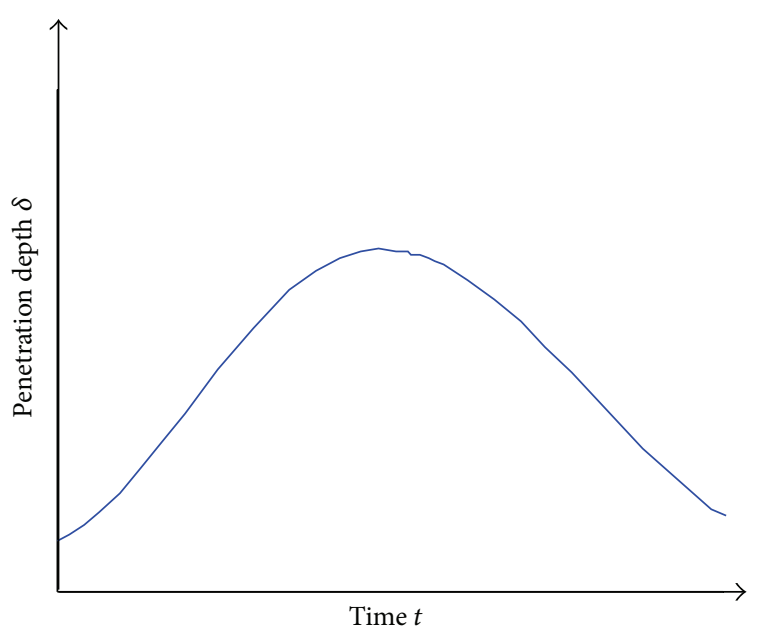

(a)

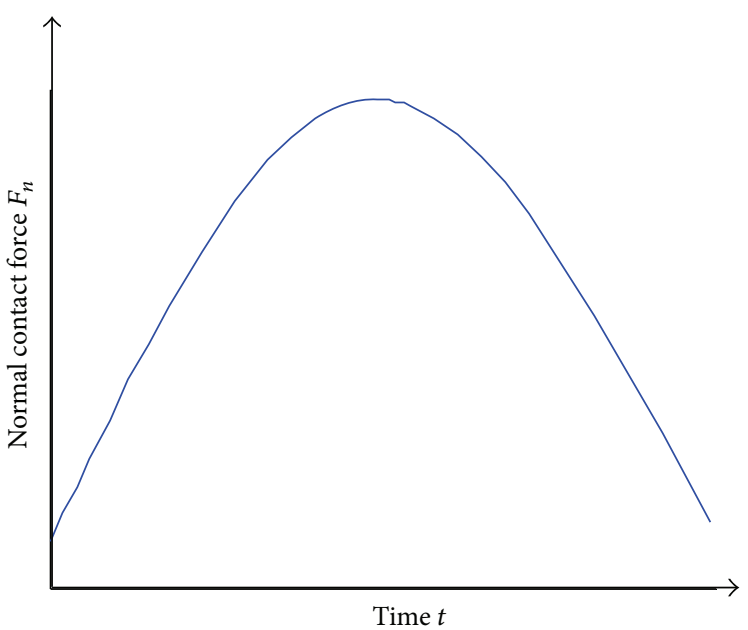

(b)

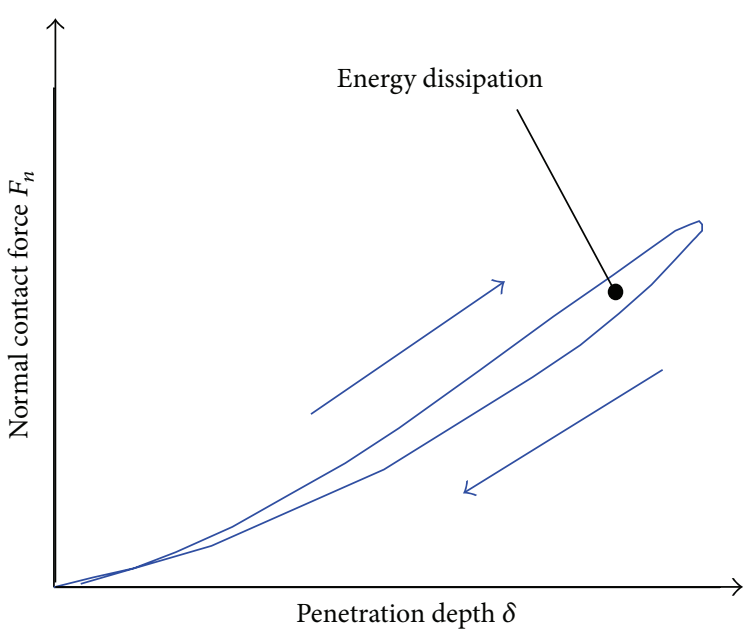

(c)

Figure 3: Lankarani and Nikravesh contact law.

In this study, the expression of nonlinear continuous contact force model is expressed in (11). Figure 3 shows penetration depth, the contact force, and the hysteretic loop for typical impact. Consider

$$
\begin{aligned}
& F_{n} \\
& = \begin{cases}0, & \delta \leq 0 \\
\frac{4}{3\left(\sigma_{1}+\sigma_{2}\right)}\left[\frac{R_{1} R_{2}}{R_{1}+R_{2}}\right]^{1 / 2} \delta^{n}+\frac{3 K\left(1-c_{e}^{2}\right) \delta^{n}}{4 \dot{\delta}^{-}} \dot{\delta}, & \delta>0 .\end{cases}
\end{aligned}
$$

2.3. Tangential Force Model. In this paper, the tangential contact force of clearance joint is calculated using a more complex friction model [21]. Friction coefficient of the model is function of tangential sliding velocity, which can avoid the abrupt change of friction in the course of numerical calculating. And also, the friction induces the viscous and microslip phenomenon in relative motion more accurately.

The tangential contact forces model can be represented by

$$
F_{t}=-\mu\left(v_{t}\right) F_{n} \frac{v_{t}}{\left|v_{t}\right|}
$$

where $v_{t}$ is the sliding velocity in tangential direction at the collision point of journal and bearing, that is, the velocity component in tangential direction. $\mu\left(v_{t}\right)$ is friction 


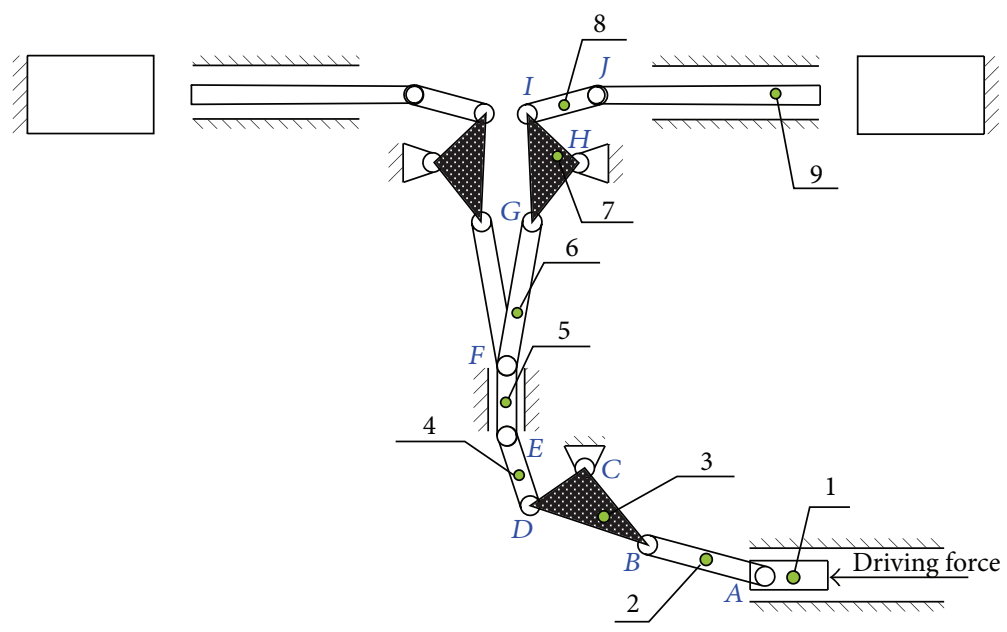
(1) Driving link
(6) Insulating pole
(2) Lower linkage
(7) Main crank arm
(3) Lower turn arm
(8) Upper linking board
(4) Lower linking board
(9) Moving contact
(5) Sealing rod

FIGURE 4: The transmission mechanism of UHV circuit breaker.

coefficient, which can be expressed as

$$
\mu\left(v_{t}\right)= \begin{cases}-\mu_{d} \operatorname{sign}\left(v_{t}\right), & \text { for }\left|v_{t}\right|>v_{d} \\ -\left\{\mu_{d}+\left(\mu_{s}-\mu_{d}\right)\left(\frac{\left|v_{t}\right|-v_{s}}{v_{d}-v_{s}}\right)^{2}\left[3-2\left(\frac{\left|v_{t}\right|-v_{s}}{v_{d}-v_{s}}\right)\right]\right\} \operatorname{sign}\left(v_{t}\right), & \text { for } v_{s}<\left|v_{t}\right|<v_{d} \\ -\mu_{s}-2 \mu_{s}\left(\frac{v_{t}+v_{s}}{2 v_{s}}\right)^{2}\left(3-\frac{v_{t}+v_{s}}{v_{s}}\right), & \text { for }\left|v_{t}\right|<v_{s},\end{cases}
$$

where $v_{d}$ is maximum critical velocity of the kinetic friction, $v_{s}$ is critical velocity of static friction, $\mu_{d}$ is kinetic friction coefficient, and $\mu_{s}$ is static friction coefficient.

\section{Numerical Modeling for Mechanism with Revolute Clearance Joints}

In this study, the transmission mechanism of UHV circuit breaker is considered as example. Compared with medium and low voltage circuit breaker, UHV circuit breaker has larger breaking current, quicker response, and higher requirement of transmission accuracy [22]. As shown in Figure 4, the mechanism which completes on/off action is a multilink combination mechanism used to transmit force and motion. The driving link is directly used to input the driving force. As the key control object of circuit breaker, moving contact, which is controlled by the control and operating system, is used to switch on/off electric current. The characteristic parameters of each component of the mechanism are listed in Table 1.
The dynamic equations of transmission mechanism are obtained by using Lagrange multiplier method. In the free motion phase, the dynamic equations are

$$
\begin{array}{r}
M \ddot{q}+C \dot{q}+K q+\phi_{q}^{T} \lambda=f, \\
\phi(q, t)=0,
\end{array}
$$

where $q$ is the generalized coordinate column matrix; $M, C$, and $K$ are the generalized mass matrix, generalized damp matrix, and generalized stiffness matrix respectively; $\phi_{q}$ is the Jacobian matrix of constraint equation; $f$ is the generalized force matrix; and $\lambda$ is the Lagrange multiplier column matrix.

In contact phase, the bodies contact and interact. So the contact forces exist in the clearances. The dynamic equations are

$$
\begin{aligned}
M \ddot{q}+C \dot{q}+K q+\phi_{q}^{T} \lambda & =f+F_{c}, \\
\phi(q, t) & =0
\end{aligned}
$$




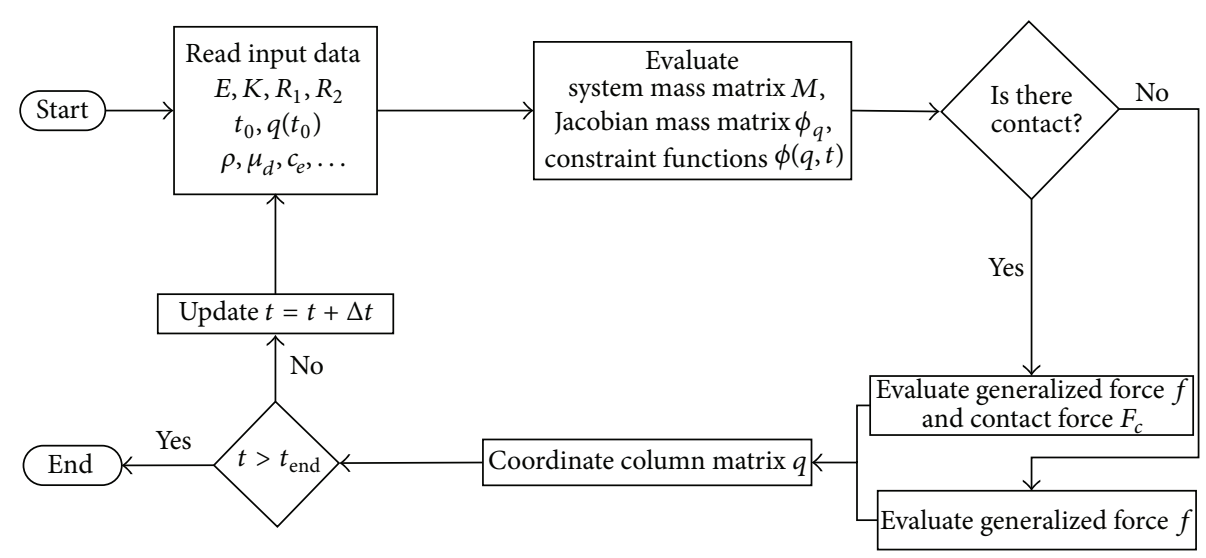

FIGURE 5: Simulation process.

TABLE 1: Parameters of the components in the mechanism.

\begin{tabular}{lcc}
\hline Body & $\begin{array}{c}\text { Mass } \\
M_{i}(\mathrm{~kg})\end{array}$ & $\begin{array}{c}\text { Moment of inertia } \\
I_{i}\left(\mathrm{~kg} \cdot \mathrm{m}^{2}\right)\end{array}$ \\
\hline 1 & 3.670 & 0.044 \\
2 & 3.720 & 0.015 \\
3 & 56.92 & 0.200 \\
4 & 4.760 & 0.010 \\
5 & 12.06 & 0.090 \\
6 & 81.54 & 0.051 \\
7 & 25.66 & 0.120 \\
8 & 13.25 & 0.027 \\
9 & 5.420 & 0.038 \\
\hline
\end{tabular}

where $F_{c}$ is the contact force, which contains normal contact force $F_{n}$ and tangential friction force $F_{t}$. And they are obtained by formulas (8) and (12) in Section 2.

The revolute joints $A$ and $B$ (Figure 4 ) of the model are modeled as clearance joints and others are ideal revolute joints. The clearance size of the revolute joint is set to be $0.01 \mathrm{~mm}$ for the present work, which is supported by manufacturing error and assemblage. Table 2 presents the parameters used in the numerical simulation of the mechanism. Its motion time is very short (totally $125 \mathrm{~ms}$ ); thus the minimum step $\left(1 \times 10^{-9}\right)$ is reasonable. The simulation process is shown in Figure 5. The calculation is on DELL7610 and the computer configuration is double nucleus processor, RAM $256 \mathrm{~GB}$. Computing time is about 1 hour.
TABLE 2: Simulation characteristics.

\begin{tabular}{lc}
\hline Stiffness coefficients $K(\mathrm{~N} / \mathrm{m})$ & $3.81 \times 10^{7}$ \\
Restitution coefficient $c_{e}$ & 0.9 \\
Static friction coefficient $\mu_{s}$ & 0.2 \\
Dynamic friction coefficient $\mu_{d}$ & 0.16 \\
Stiction translation velocity $v_{s}(\mathrm{~m} / \mathrm{s})$ & $1.0 \times 10^{-4}$ \\
Friction translation velocity $v_{d}(\mathrm{~m} / \mathrm{s})$ & $1.0 \times 10^{-2}$ \\
Density $\rho\left(\mathrm{kg} / \mathrm{m}^{3}\right)$ & $7.8 \times 10^{3}$ \\
Radius of the solids in contact $R(\mathrm{~m})$ & 0.05 \\
Max. time step & $1.0 \times 10^{-3}$ \\
Min. time step & $1.0 \times 10^{-8}$ \\
Accuracy & $1.0 \times 10^{-7}$ \\
Jacobian pattern & $100 \%$ \\
\hline
\end{tabular}

\section{Experimental Verification and Results Analysis}

4.1. Experimental Verification. The displacement and velocity of transmission mechanism for UHV, which directly indicate the motion characteristics of the moving contact at the output end, are key parameters to determine the interrupting ability of the circuit breaker in transmission motion. The characteristics of the mechanism such as compact structure, small space, and airtight requirement are considered, which make the layout of the sensor at the moving contact unable to be implemented. Therefore, the displacement of sealing rod and the rotational angular velocity of lower turn arm are measured. Finally, the movement parameters measured during experimental test are converted to those of moving contact through geometry calculation. 


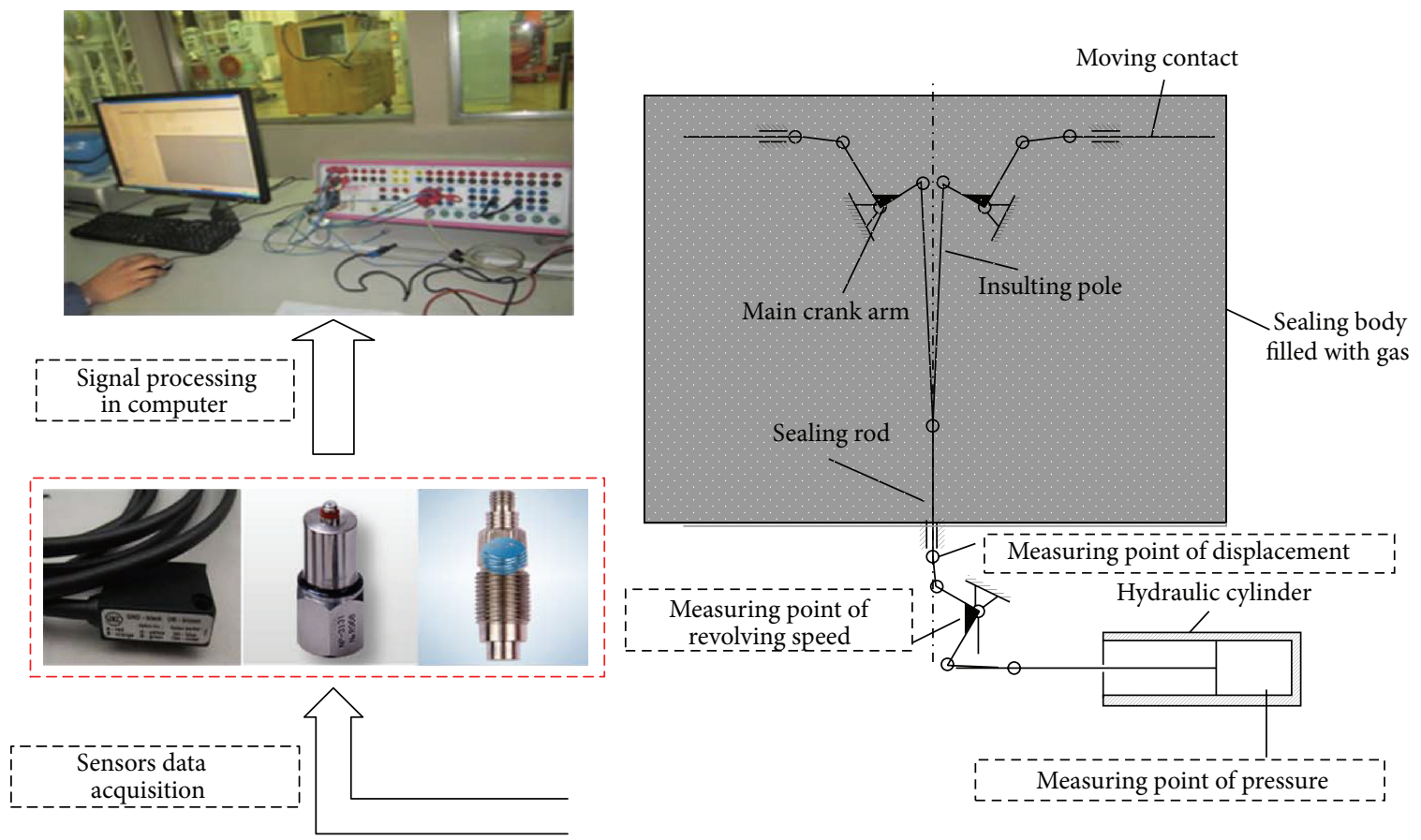

FIGURE 6: Experimental test system.

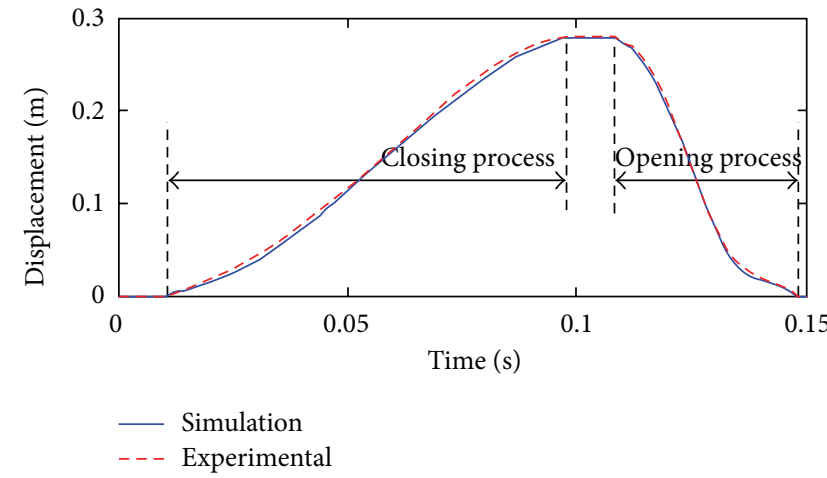

(a) Displacement of moving contact

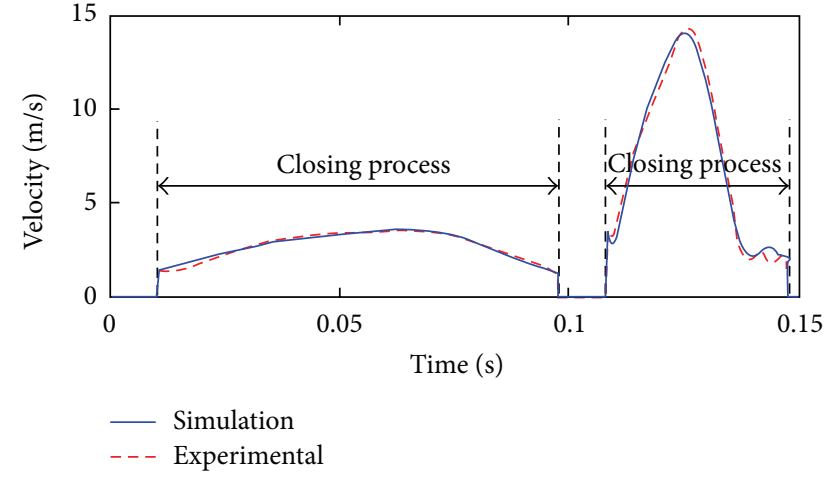

(b) Velocity of moving contact

Figure 7: Results of experimental and simulation with clearance joints.

The experimental test principle is shown in Figure 6. The test system is German's ACTAS test system which can test and analyze the results automatically. It has reliability and interference immunity in various complex electromagnetic environments. And it can confirm high accuracy and linear frequency responses on the treatment of experimental data. Meanwhile, it can measure the relevant physical quantities simultaneously and analyze the results automatically. The displacement of sealing rod is measured by using magnetic railings ruler, which can reduce the negative impact of vibration on the experimental test. The rotational angular velocity of lower turn arm is measured by using ROS photoelectric rotating-speed sensor, which can avoid the influence of extra load on the experimental test. Because the mechanism has the characteristics of short working time, fast response, and high speed of movement, the sampling frequency of the sensor which is used for testing is $15000 \mathrm{~Hz}$. Finally its curves of displacement and velocity are obtained after the noise signal is filtered out.

During the numerical simulation, Figure 7 shows a comparison between the experimental and simulation results. It is shown that the simulation and experimental results are in good agreement. This shows that the simulation model established in this paper has a certain accuracy.

4.2. Dynamic Responses. During the dynamic simulation, the revolute joint $J$ (Figure 4) of the model is modeled as clearance joint and others are ideal revolute joints. Equation 


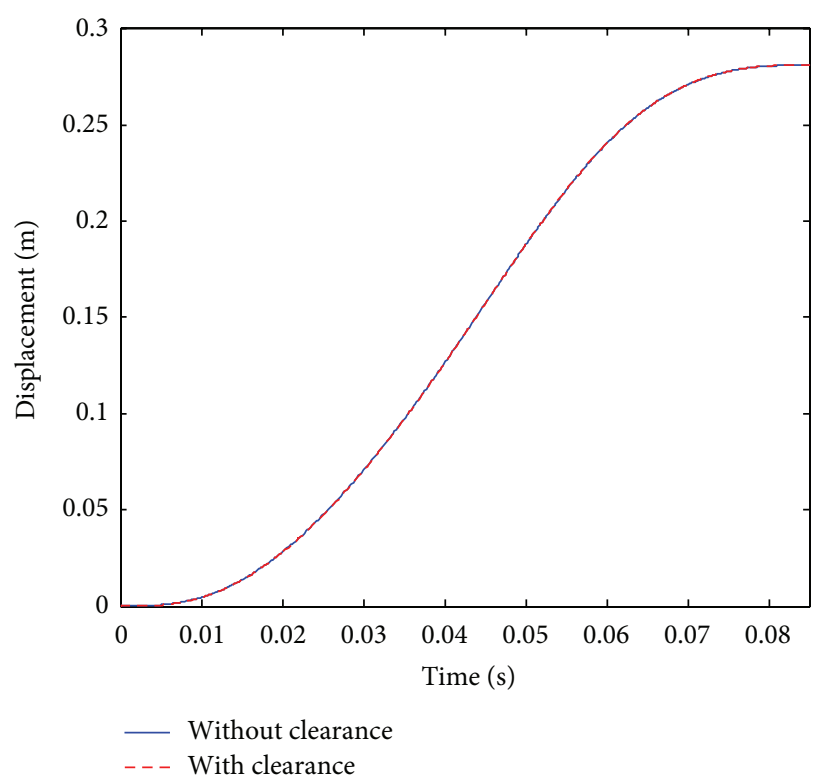

(a) Displacement

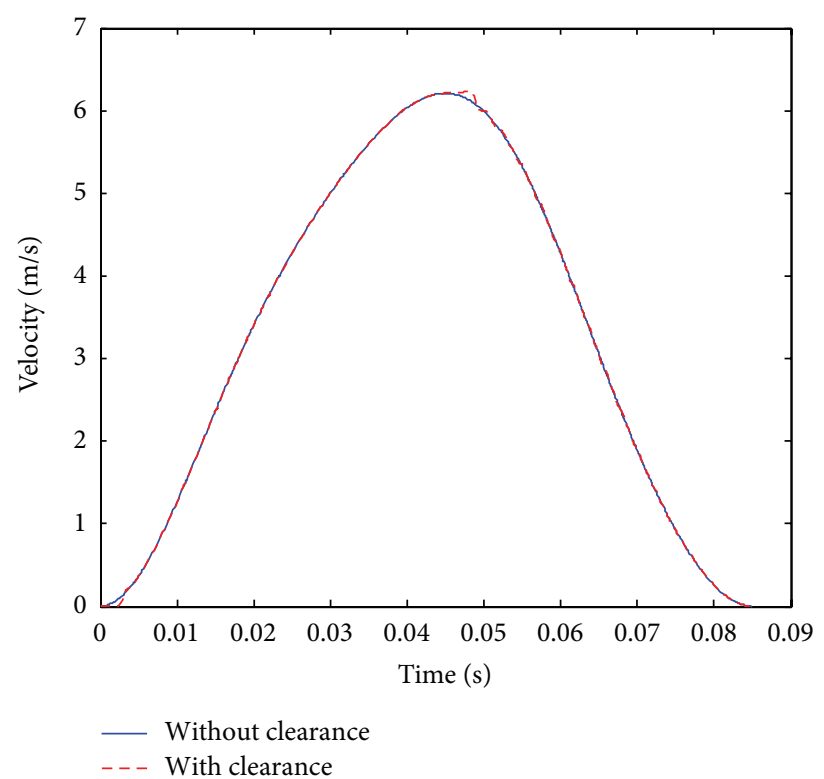

(b) Velocity

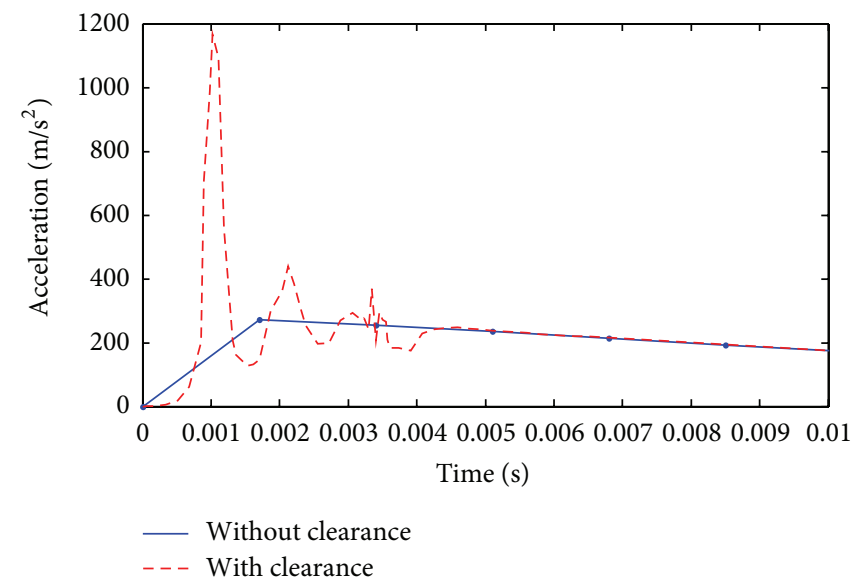

(c) Acceleration

FIGURE 8: Dynamic responses for simulation model.

(16) is selected as input function of driving link. The clearance size of the clearance joint is set to $0.01 \mathrm{~mm}$, while the simulation time duration is $0.085 \mathrm{~s}$. The displacement, velocity, and acceleration of the moving contact for the simulation model are shown in Figure 8. Consider

$$
= \begin{cases}0, & T=0 \\ -0.23 *\left(\frac{T}{0.085}\right)^{2} *\left(3-\frac{2 T}{0.085}\right), & 0<T<0.085 \\ -0.23, & T=0.085 .\end{cases}
$$

As can be observed from Figure 8, the influences of clearance on acceleration of the mechanism are severer than the influences of clearance on displacement and velocity. The displacement and velocity of the mechanism with clearance are generally consistent with those without clearance. Remarkably the existence of clearance joint induces the highfrequency shake of acceleration, and peak value of acceleration of the mechanism is 3.58 times more than that of the mechanism without clearance. It is clear that the existence of the clearance joints has an important influence on the dynamic response of the mechanism, and the clearance joints must be considered for dynamic analysis of the mechanisms.

4.3. Clearance Sizes. The effect of the clearance size on the dynamic responses of the mechanism is investigated. During the dynamic simulation, the revolute joints $A$ and $J$ (shown in Figure 4) are modeled as clearance joints and others are ideal revolute joints. Four cases studies are implemented for the different clearance sizes of $0.01 \mathrm{~mm}, 0.03 \mathrm{~mm}, 0.05 \mathrm{~mm}$, and $0.1 \mathrm{~mm}$. The velocity and acceleration of the moving contact for different clearance sizes are shown in Figure 9. 


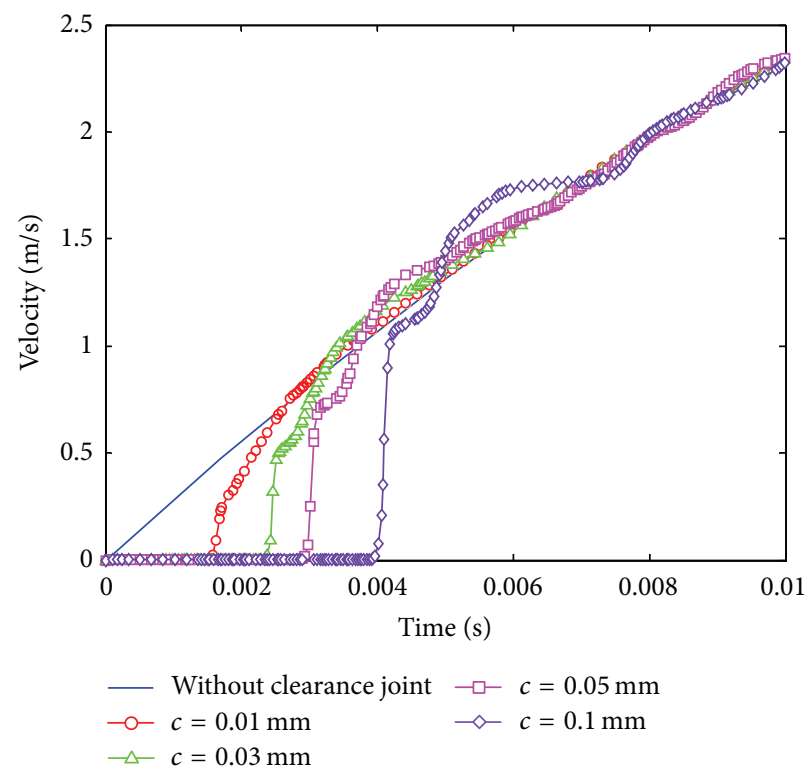

(a) Velocity of different clearance sizes

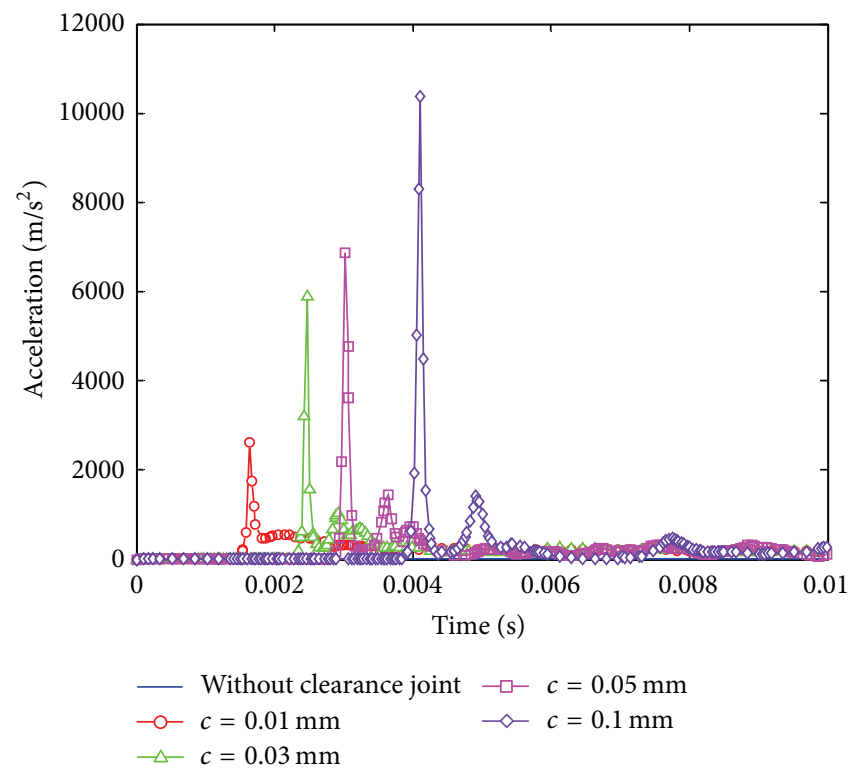

(b) Acceleration of different clearance sizes

FIGURE 9: Influence of different clearance sizes.

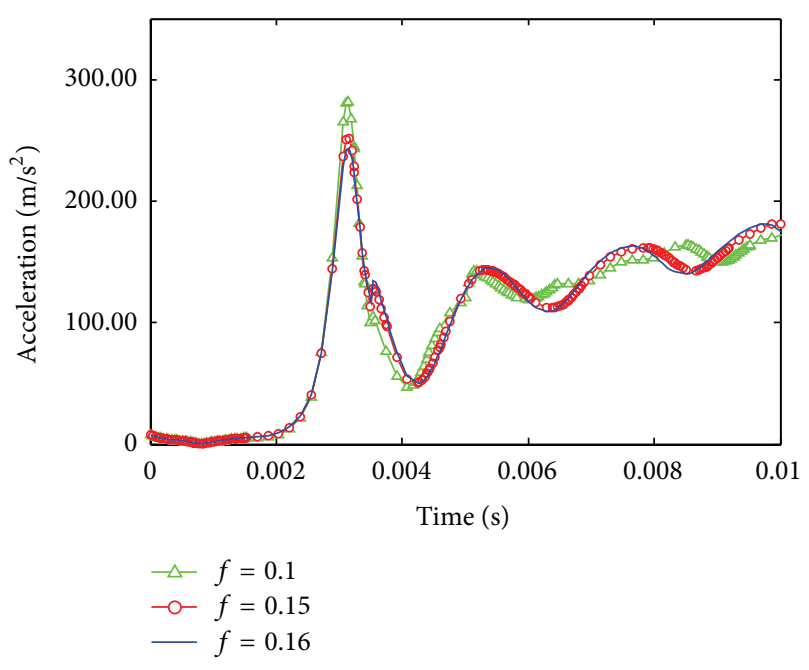

FIGURE 10: Responses for different friction coefficient in joints.

As can be seen from Figure 9(a), in time domain the more the clearance size increases, the more obvious the fluctuation frequency and the hysteretic nature of velocity are. When the clearance size in revolute joint increases from $0.01 \mathrm{~mm}$ to $0.1 \mathrm{~mm}$, the time delay of velocity in the starting stage of motion increases from $0.0016 \mathrm{~s}$ to $0.0042 \mathrm{~s}$. Although the time is very short, it will lead to a kinematic error about $8.5 \%$ for the mechanism with characteristics of high speed and heavy load. This might cause a huge negative effect in closing and opening process.
As can be seen from Figure 9(b), the simulation results also show that the acceleration of the mechanism is influenced by clearance size strongly, especially for the highspeed mechanism. With the clearance size increasing from $0.01 \mathrm{~mm}$ to $0.1 \mathrm{~mm}$, the peak value of acceleration increased remarkably, from $2325.6 \mathrm{~m} / \mathrm{s}^{2}$ to $10345.5 \mathrm{~m} / \mathrm{s}^{2}$ (increased about 4 times). This excessive impact will greatly reduce the dynamic characteristics of the mechanism.

4.4. Friction Coefficient. The influence of different friction coefficient in joints is reported in this section. The revolute joints $A$ and $J$ (shown in Figure 4 ) are modeled as clearance joints, when the clearance size is $0.1 \mathrm{~mm}$ and input time is $0.085 \mathrm{~s}$. The acceleration of the rigid model with clearance for different friction coefficients is shown in Figure 10.

It can be seen from Figure 10 that, with the friction coefficient increasing, the peak value of the acceleration decreases slightly. When the friction coefficient increases from 0.1 to 0.16 , the peak value of acceleration decreases from $2815.4 \mathrm{~m} / \mathrm{s}^{2}$ to $2326.6 \mathrm{~m} / \mathrm{s}^{2}$. The simulation results indicate that different friction coefficients have effect on the dynamic response of mechanism in a significant manner. This also reveals that increase of friction coefficient leads to a better response of the mechanical system.

4.5. Journal Center Path Relative to Bearing Center. Figure 11 depicts the relative motion between the journal and bearing centers in the upper linking board and the moving contact. The result indicates that the paths of journal center have three modes of motion inside the bearing internal surface of clearance joint. Three different modes of motion between the bearing and journal during dynamic of the clearance joint can 


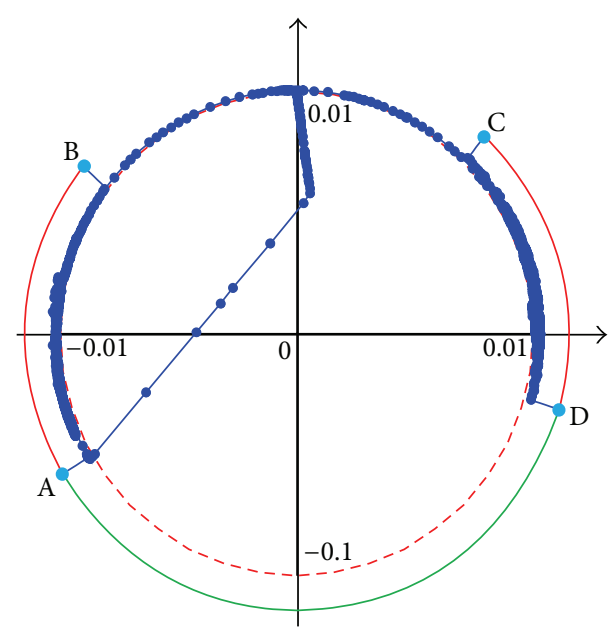

FIGURE 11: The journal center path of clearance joint $J$.

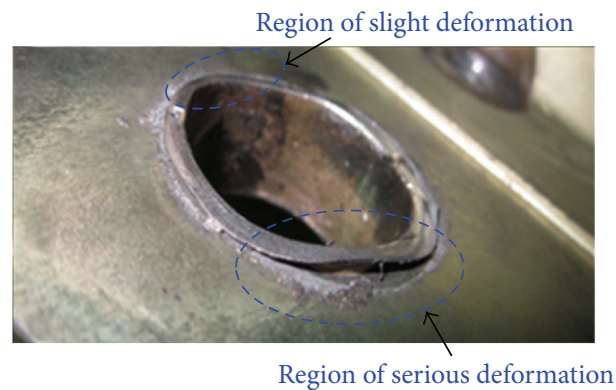

FIgURE 12: Deformation region.

be noticed: (a) free flight mode (namely, the journal center that lies inside the clearance circle moves freely within the bearing internal surface), (b) impact mode (it presents at the end of the free flight mode; namely, the presence of the journal center exactly on the circumference of the clearance circle shows that it moves tangent to the bearing internal surface), and (c) continuous contact mode (i.e., the journal center lies beyond the clearance circle, which indicates that the journal penetrates inside the bearing surface). It can be observed that the journal spends long periods sticking to the bearing boundaries in contrast to the free flight period; the reason is the energy dissipation due to impact as stated by Lankarani and Nikravesh.

It can be clearly found out from Figure 11 that the motion of the journal center is not evenly distributed along the circle. The most drastic contact and impact occur in regions $\mathrm{AB}$ and $\mathrm{CD}$. When they get into contact within these two areas, the repeated violent impacts will lead to the considerable serious extrusion, however, a small region $\mathrm{AD}$ of which does not show any deformation. The interaction between the pin and sleeve is not in the whole circle from the actual situation shown in Figure 12. The region of serious deformation is in a short arc length. This is in agreement with the simulation results.

\section{Conclusions}

A computational methodology is provided to analyze the dynamic characteristics of transmission mechanism with clearance joints, and it can predict the effects of clearance on transmission mechanism preferably, which is the basis for precision analysis, optimization design of transmission mechanism, and reliability operation of breaker circuit.

In this work, a model of the transmission mechanism of UHV with multiple clearances is established by using the Lankarani and Nikravesh contact theory and the modified Coulomb friction model. The contact model used to simulate contact force in the clearance joints is based on subroutines "cnfsub.c". The numerical simulation results agree well with experimental data. Since the reliability of mechanism is proved in this simulation, physical experiments can be replaced by computer simulation, which will save much time and cost for a new design of circuit breakers.

The dynamic response of the mechanism is influenced greatly by the clearance. In comparison with ideal models, those with the presence of multiple clearances cause not only hysteresis effect on velocity and acceleration of the mechanism but also impacts as well as fluctuations in the latter. With the increase of clearance size such delay and impacts will become more significant. In addition, when the dynamic friction coefficient increases, the dynamics response of mechanism becomes less shaky. Therefore, the increase of dynamic friction coefficient leads to a better response.

Journal is the major component of the transmission mechanism. This investigation also indicates that its center motion path during the work process of the model, which is unevenly distributed along circle, goes through three phases, involving free flight motion and contact motion, along with impact motion. The region of serious deformation is in a short arc length. This is in agreement with the actual situation.

\section{Conflict of Interests}

The authors declare that there is no conflict of interests regarding the publication of this paper.

\section{Acknowledgments}

The authors would like to express sincere gratitude to the National Natural Science Foundation of China "Research on Load Sharing Characteristics of High-Power and HeavyLoad Compound Planetary Gear Transmission System (no. 51375350)" and the Postdoctoral Science Foundation of China "Research of Multi-Domain Modeling Theory and Methods for Mechanical-Electrical-Hydraulic Coupling System of UHV Breaker (no. 2014M562056).”

\section{References}

[1] J. Alves, N. Peixinho, M. T. Da Silva, P. Flores, and H. M. Lankarani, "A comparative study of the viscoelastic constitutive models for frictionless contact interfaces in solids," Mechanism and Machine Theory, vol. 85, pp. 172-188, 2015. 
[2] Z.-F. Bai and Y. Zhao, "Dynamics simulation of deployment for solar panels with hinge clearance," Journal of Harbin Institute of Technology, vol. 41, no. 3, pp. 11-14, 2009.

[3] E. Zheng and X. Zhou, "Modeling and simulation of flexible slider-crank mechanism with clearance for a closed high speed press system," Mechanism and Machine Theory, vol. 74, pp. 1030, 2014.

[4] P. Flores and H. M. Lankarani, "Dynamic response of multibody systems with multiple clearance joints," Journal of Computational and Nonlinear Dynamics, vol. 7, no. 3, Article ID 031003, pp. 1-13, 2012.

[5] P. Flores, M. MacHado, M. T. Silva, and J. M. Martins, "On the continuous contact force models for soft materials in multibody dynamics," Multibody System Dynamics, vol. 25, no. 3, pp. 357375, 2011.

[6] M. MacHado, J. Costa, E. Seabra, and P. Flores, "The effect of the lubricated revolute joint parameters and hydrodynamic force models on the dynamic response of planar multibody systems," Nonlinear Dynamics, vol. 69, no. 1-2, pp. 635-654, 2012.

[7] S. Mukras, N. H. Kim, N. A. Mauntler, T. Schmitz, and W. G. Sawyer, "Comparison between elastic foundation and contact force model in wear analysis of planar mutibody system," Journal of Tribology, vol. 132, no. 3, Article ID 031604, 11 pages, 2010.

[8] S. Mukras, N. H. Kim, N. A. Mauntler, T. L. Schmitz, and W. G. Sawyer, "Analysis of planar multibody systems with revolute joint wear," Wear, vol. 268, no. 5-6, pp. 643-652, 2010.

[9] T.-N. Shiau, Y.-J. Tsai, and M.-S. Tsai, "Nonlinear dynamic analysis of a parallel mechanism with consideration of joint effects," Mechanism and Machine Theory, vol. 43, no. 4, pp. 491-505, 2008.

[10] S. Erkaya and İ. Uzmay, "Determining link parameters using genetic algorithm in mechanisms with joint clearance," Mechanism and Machine Theory, vol. 44, no. 1, pp. 222-234, 2009.

[11] Q. Tian, Y. Zhang, L. Chen, and J. Z. Yang, "Simulation of planar flexible multibody systems with clearance and lubricated revolute joints," Nonlinear Dynamics, vol. 60, no. 4, pp. 489-511, 2010.

[12] Q. Tian, C. Liu, M. MacHado, and P. Flores, "A new model for dry and lubricated cylindrical joints with clearance in spatial flexible multibody systems," Nonlinear Dynamics, vol. 64, no. 1, pp. 25-47, 2011.

[13] Q. Tian, Y. Sun, C. Liu, H. Hu, and P. Flores, "Elastohydrodynamic lubricated cylindrical joints for rigid-flexible multibody dynamics," Computers and Structures, vol. 114-115, pp. 106-120, 2013.

[14] Z. Zhang, L. Xu, P. Flores, and H. M. Lankarani, "A Kriging model for dynamics of mechanical systems with revolute joint clearances," Journal of Computational and Nonlinear Dynamics, vol. 9, no. 3, Article ID 031013, pp. 1-13, 2014.

[15] S. M. Varedi, H. M. Daniali, M. Dardel, and A. Fathi, "Optimal dynamic design of a planar slider-crank mechanism with a joint clearance," Mechanism and Machine Theory, vol. 86, pp. 191-200, 2015.

[16] Y. F. Liu, J. Li, Z. M. Zhang, X. H. Hu, and W. J. Zhang, "Experimental comparison of five friction models on the same test-bed of the micro stick-slip motion system," Mechanical Sciences, vol. 6, no. 1, pp. 15-28, 2015.

[17] I. Khemili and L. Romdhane, "Dynamic analysis of a flexible slider-crank mechanism with clearance," European Journal of Mechanics, A/Solids, vol. 27, no. 5, pp. 882-898, 2008.
[18] C. S. Koshy, P. Flores, and H. M. Lankarani, "Study of the effect of contact force model on the dynamic response of mechanical systems with dry clearance joints: computational and experimental approaches," Nonlinear Dynamics, vol. 73, no. 1-2, pp. 325-338, 2013.

[19] S. Erkaya, S. Doğan, and Ş. Ulus, "Effects of joint clearance on the dynamics of a partly compliant mechanism: numerical and experimental studies," Mechanism and Machine Theory, vol. 88, pp. 125-140, 2015.

[20] A. L. Schwab, J. P. Meijaard, and P. Meijers, "A comparison of revolute joint clearance models in the dynamic analysis of rigid and elastic mechanical systems," Mechanism and Machine Theory, vol. 37, no. 9, pp. 895-913, 2007.

[21] Z.-F. Bai, Y. Zhao, and Z.-G. Zhao, "Dynamic characteristics of mechanisms with joint clearance," Journal of Vibration and Shock, vol. 30, no. 11, pp. 17-21, 2011.

[22] W. Liu and B. Xu, "Characteristic analysis of high voltage circuit breaker with hydraulic operating mechanism," Journal of Mechanical Engineering, vol. 46, no. 10, pp. 148-155, 2010. 


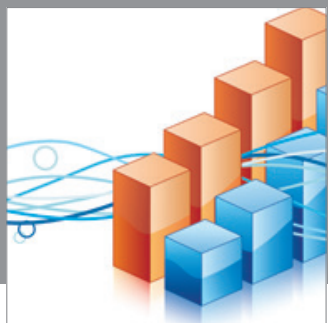

Advances in

Operations Research

mansans

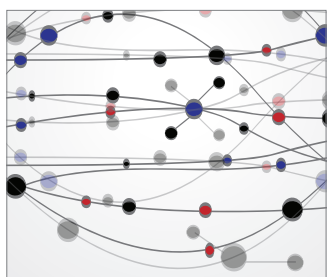

The Scientific World Journal
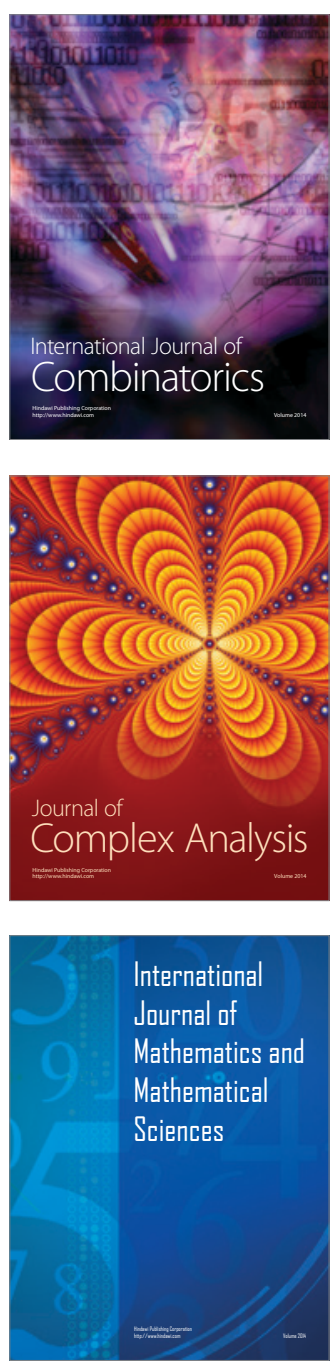
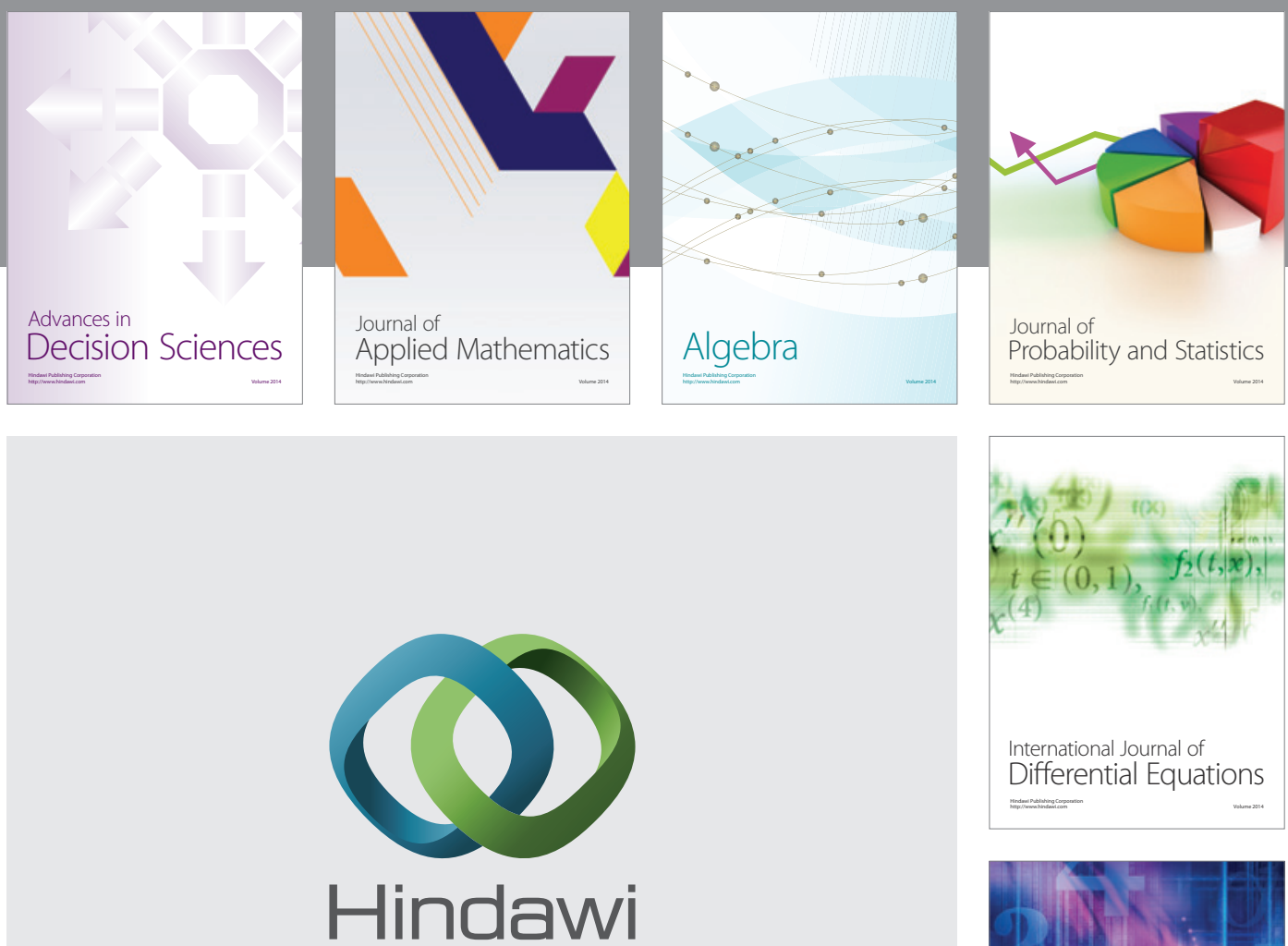

Submit your manuscripts at http://www.hindawi.com
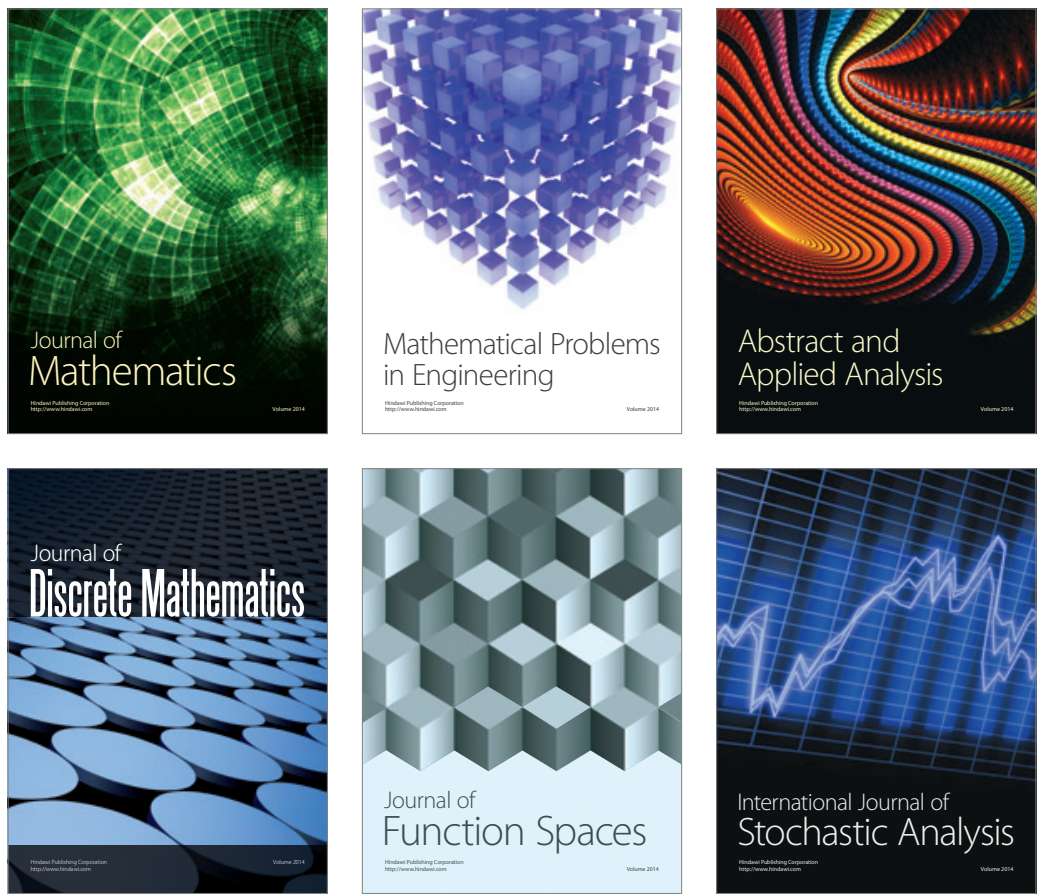

Journal of

Function Spaces

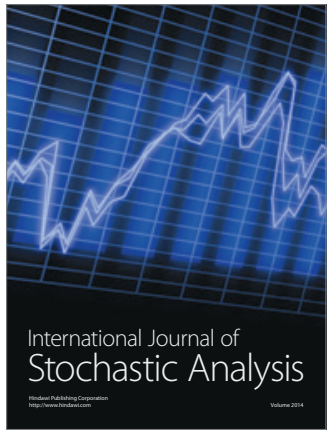

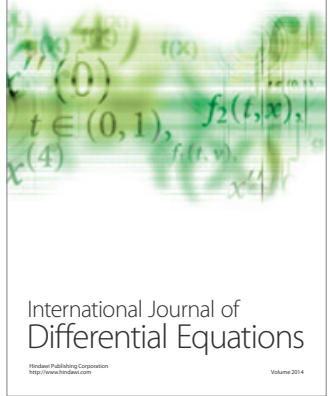
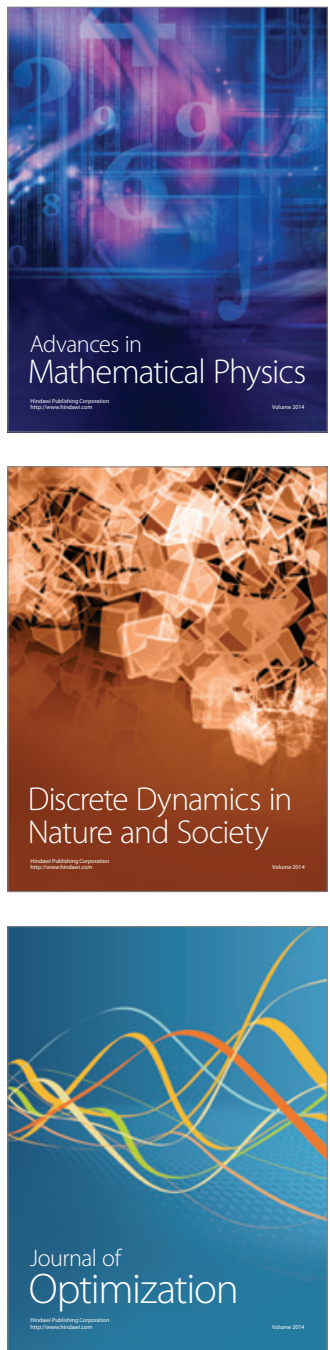